Article

\title{
The Impact of Multisensory Instruction on Geosciences Learning and Students' Motivation
}

\author{
Fábio Miguel Ferreira *(i) and Clara Vasconcelos (1) \\ CIIMAR, Faculty of Sciences, Porto University, Rua do Campo Alegre, 4169-007 Porto, Portugal; \\ csvascon@fc.up.pt \\ * Correspondence: fferreira@fc.up.pt
}

Received: 29 September 2020; Accepted: 16 November 2020; Published: 19 November 2020

\begin{abstract}
We live in a multisensory world. However, in classrooms, unisensory approaches are preferred, although they are unnatural and usually demotivating for youngsters. We conducted this mix-method study to investigate the possible effects of a multisensory approach on geosciences learning among students at a primary school in Porto, Portugal. The cognitive outcome was assessed using a pre/post-test design, while motivation and other attitudinal parameters were studied using an anonymous questionnaire. The results revealed a higher mean score in post-tests for students attending multisensory classes and high levels of motivation. Therefore, we consider that multisensory instruction has a positive impact on geosciences learning and motivation, and proper measures should be adopted to propel its full and optimal application in schools.
\end{abstract}

Keywords: geosciences learning and teaching; multisensory instruction; student motivation; distance education

\section{Introduction}

\subsection{Multisensory Instruction}

Since the beginning of humanity, learning has never been solely a unisensory process. For instance, for most jobs, practical training is required to ensure the best type of apprentice training, involving listening, careful observation, and, mostly, manipulation. Even at a more theoretical level, listening and writing would hardly be enough for most students to achieve a greater level of knowledge, or it would be more difficult. That is because such a scenario is not natural to us. That was first proven by Orton in the 1920s [1], who recorded the use of multisensory techniques in dyslexia, involving visual, auditory, and kinesthetic modalities with great results on overcoming dyslexic reading problems. Since then, several multisensory techniques have been developed to facilitate learning in people with visual or hearing difficulties [2]. Even before, Montessori realized the importance of our senses and multimodal perception, which is part of her method [3]. Still, teaching is yet generally conceived as didactic, with information being passed down by the educator, and ignoring the power of graphical tools and movement, for example. This mode of teaching usually generates many alternative concepts in children that are difficult to eradicate [4].

Multisensory approaches take advantage of the impact of the senses on the learning process and the importance of body, or kinesthetic, movements. When students invoke more than one sense to create mental representations of objects, concepts, or phenomena, they tend to interact with them more intensely and, thus, retain what they learn for longer periods. In subsequent contact, another multisensory or unisensory stimulus makes it easier to access that memory (for a comprehensive review, see $[5,6])$. In multisensory learning, the teacher engages students through at least two stimuli of different senses, be they visual, auditory, or even involving their taste, smell, and tactile stimuli, and then 
links the activity to relevant academic objectives. This extends to multiple means of presentation, of involvement, and of evaluation [7].

Most abstract notions can be taught using several sensory techniques. It is important for students to experience concepts through a variety of meanings, build a variety of representations, and the connections between them, to create a more flexible understanding of the idea, concept, or phenomenon that is being taught. However, this does not necessarily imply the presentation of ideas using all the senses simultaneously. Preferably, there must be a natural relationship between stimuli; they must be congruent and consistent with the individual's previous experience. It is through the reciprocal relationship between the sensorial input and the cognition that multisensory techniques gain power [6].

Despite the increasing recognition of the benefits of multisensory learning by scientists and educators, coupled with increasing technological development, multisensory learning is still not used to its full potential. Multisensory learning in Portuguese schools and, specifically, in earth science-related classes, has not gone beyond the occasional study (for example, reference [8] or fragmented approaches, mostly a consequence of the nature of the field under study, materialized, such as visual representations and laboratory classes). This is in contrast with the ease with which regular science classes may promote creative learning. Creativity is fundamental to incorporating multisensory approaches in the classroom, and it is often impaired by distance learning [9]. This current year, 2020, the coronavirus disease 2019 (COVID-19) pandemic worldwide has posed challenges to our society and educational systems, shifting almost entirely the regular classroom lessons to distance education environments. The learning consequences of such radical changes are yet to be completely understood, but recognizing the effects is essential in weighing the pros and cons of distance learning and improving its implementation in the future.

\subsection{Minerals: Human Health, Earth System, and Sustainability}

Earth is the main life support system, supplying our basic needs for minerals, water, and air. The growing interest in further understanding of how the Earth works as a system is partly due to the link between geology and health. For that reason, the development of Earth system science education is growing as a required need for the Earth's sustainability and the students' development of competences $[10,11]$. In the past two centuries, physicians and geoscientists have managed to establish links between the geological frameworks of some areas and the incidences of certain diseases [12]. The compositions of rocks and minerals are reflected in the air we breathe, the water we drink, and the food we eat. The transfer of minerals-and the trace, essential, or nonessential toxic elements they contain - can occur by contact, either inhalation or, more often, by ingestion and absorption. Mineral salts play an essential role in our normal metabolism and physiological functions in various molecular and cellular processes. More than two dozen elements, mostly metals or metalloids, are known or considered "essential" to stay healthy [13].

The levels of exploitation of the Earth's geological resources, combined with bioavailability and the consequent biological absorption, are among the many complex variables that influence human well-being and longevity [14]. Possible changes in the soil composition caused by the extraction, enrichment, and consumption of natural resources are often related to harmful side effects that involve environmental degradation and a decreased general viability of the biosphere and, concomitantly, poses a threat to human health [13]. Therefore, as defined by the United Nations in the 17 Sustainable Development Goals (SDGs) in the so-called 2030 Agenda [15], issues related to education and safer, more sustainable and healthier diets, including access to drinking water, appear as pressing study problems that must be the target of contextualized teaching in science education.

The main purpose of this study was to explore the relative effectiveness on cognitive performance and the motivation of two modes of instruction-multisensory instruction and traditional instruction based on textbook written exercises - on grade 9 (theoretically, aged 14-15 years) students, while aiming to meet the UN's global request. Three sessions dedicated to the importance of minerals in human health in relation with the geosphere and its sustainability were taught in 9th-grade classes of a 
Northern Portuguese school, in Porto, during a year of transition between regular and distance learning imposed by the COVID-19 pandemic worldwide.

The main question was to explore whether the use of multisensory instruction enhances the development of students' cognitive performances and motivations relative to common traditional exercise-solving classes under the theme of minerals as a link between the Earth and human health. The hypothesis "There is a positive relationship between multisensory instruction and students' cognitive performances in geoscience lessons" was tested in this research.

\section{Materials and Methods}

\subsection{Procedures}

A mixed-method study was applied and split into two phases. During the first term, a quasi-experimental study was conducted, with students nonrandomly assigned to groups, since the classes were formed at the beginning of the academic year by the school's administration. All the 9th graders were asked to complete a pretest after the first identical theoretical lesson but before the second lesson involving reinforcement. Then, one group was included in a reinforcement lesson driven by a multisensory approach (experimental group), while the other group participated in a reinforcement lesson consisting of textbook written exercises-the traditional method (control group). More than one week later, all students completed a post-test—an alternate form, structurally and conceptually very similar to the pretest- to check the effect of multisensory learning on cognitive performance. Both tests were applied several weeks before the corresponding regular school assessment. All students were taught by their science teacher. The duration of lessons was the same between groups, $50 \mathrm{~min}$ for each lesson.

In the second phase, the experimental group participated in two other sessions based on multisensory approaches during the second and third terms, respectively. At the end of the second phase, the same group completed simultaneously an anonymous online questionnaire about their opinions and experiences regarding the three sessions to evaluate the effects of multisensory learning on attitudinal development-namely, on their motivation.

The multisensory approaches undertaken on the three sessions comprised different strategies, each in association with specific perceptual modalities. Some of these strategies were systematically used, including graphical representations, texts to read, as well as lists, and worksheets to complete, always interspersed with explanations, questions, and discussion, while other strategies were exclusively prepared for each of the sessions. These included blinded food tasting, brief improvised role-plays, models to construct and explore, the dissection of rabbit kidneys, and analyses of minerals/rocks. For the last session, during the third term, besides worksheets, online breakout games, termed "The Killer Element" and based on real-life situations, were constructed and selected as an adaptation to distance learning. The interactive sequential games also included graphical representations, videos, texts, and connected songs.

The main themes under study were based on mineral salts, regarding their characteristics, medical conditions associated with excess and deficiency in our body, richest food sources, rocks/minerals sources, and national and international-associated mining.

For a more traditional approach, the textbook chosen by the school (from one of the options defined by the Ministry of Education) was used as a source of written exercises on the above topic, which were completed by students and, finally, corrected by the teacher.

Regarding the multisensory approach, the students were asked to role-play "chefs", "surgeons", and "inspectors" in each of the three sessions. To provide the information, and in addition to the designated textbook, fact sheets (infographic and text versions) were used in all multisensory lessons, as well as discussions, questioning, and explanations as a whole group. Blinded food tasting was used as an activity of "guess which food" after each student selected a specific mineral salt, short role-plays were devoted to an improvised mimicking activity of "guess which disease" performed 
by students after having selected a specific mineral salt, and the dissection of rabbit kidneys and the assembling and exploration of nephron-constructed models were used as laboratory activities to closely study the organ and structure, respectively, where mineral salts are reabsorbed or excreted; rocks and minerals formed by each of the studied salt minerals were displayed for handling and analyses by students, together with important national mining names linked to them. Worksheets were completed progressively to summarize all the information collected on each of the studied mineral salts (see Figure 1).

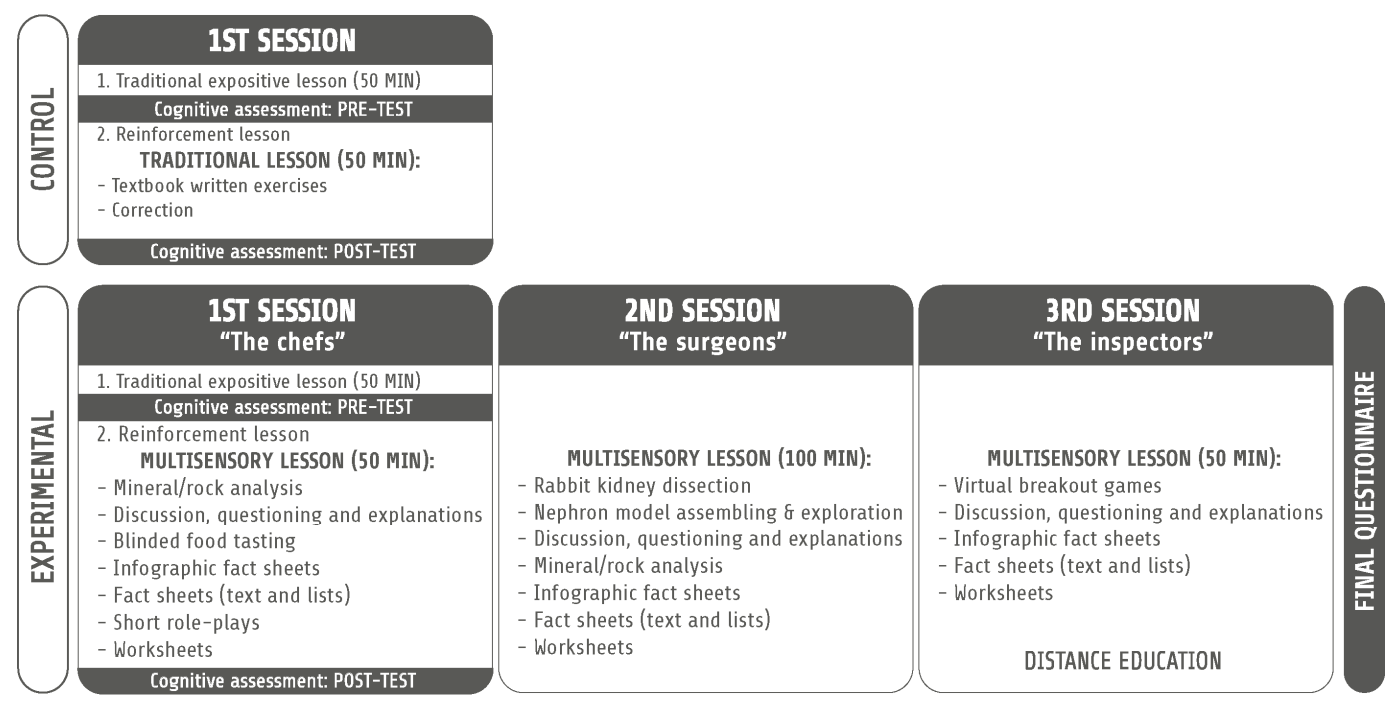

Figure 1. Workflow with the control group and the experimental group, including all strategies/activities selected for each session and the instruments of assessment applied.

\subsection{Sample}

From all the ninth graders in a Northern Portuguese school (in Porto), included in the first phase, 80 students completed both pre- and post-tests. The age of the students in this sample spanned from 13 to 17 years old (median $=14$ years) at the beginning of the school year. Gender in the sample was evenly distributed (41 girls and 39 boys). Moreover, $21 \%$ of students were held back in the previous school year. Each class was assigned to each of the two groups (control and experimental) according to the total number of students and general final classifications in previous science courses to achieve approximate equality between the groups (control group, $n=38$ and experimental group, $n=42$ ). The selection of which of the two groups of students would continue with the second phase (second and third multisensory sessions) was determined by the availability of the science teacher. All subjects gave their informed consent for inclusion before they participated in the study. The study was conducted in accordance with the protocol approved by the ethics committee of the authors' university. Table 1 summarizes the sample distribution.

Table 1. Sample distribution.

\begin{tabular}{ccccc}
\hline & Male $(\mathbf{n}=\mathbf{3 9})$ & Female $(\mathbf{n}=\mathbf{4 1})$ & Age Range & Previous School Year Failing \\
\hline Control group $(\mathrm{n}=38)$ & 12 & 26 & $13-17$ & 17 \\
Experimental group $(\mathrm{n}=42)$ & 27 & 15 & $13-16$ & 10 \\
\hline
\end{tabular}

\subsection{Instruments}

Both the pretest and post-test consisted of four groups of questions, including multiple choice, short answer, linking questions, or correspondences to complete. Each question from both tests focused on one of the topics included in the theme, as developed in the textbook designated by the school for this course, to ensure that both tests covered the content of the textbook-based and the multisensory lessons 
equally. Moreover, questions were mostly of low order, according to Bloom's Taxonomy [16], based on the knowledge and comprehension assessment (see examples in Table 2). The alternate form for the post-test was selected as an equivalent form in terms of content, response processes, and statistical characteristics in order to avoid carryover effects and, partially, reactivity effects. Although questions generally asked for closed answers, the tests were independently graded by two teachers and matched to guarantee fairness in the assessment.

Table 2. Examples of questions used in pre- and post-tests for three of the studied topics.

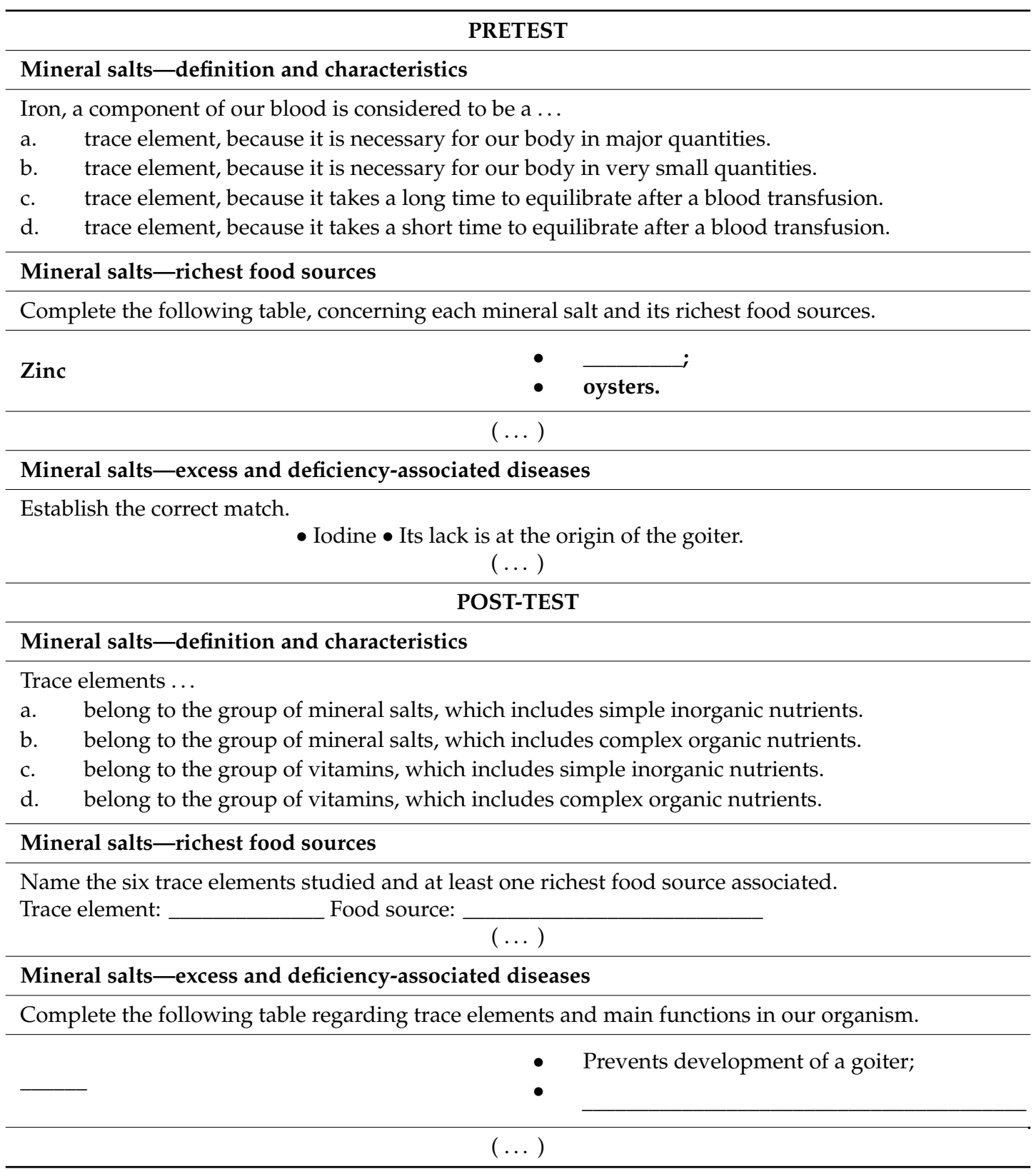

An anonymous quasi-structured questionnaire, including closed and open-ended questions, was constructed and made available online one week after the third session to survey the reactions of students toward the multisensory experience and attitudinal changes. The questionnaire consisted of eight Likert-scale questions, focused on students' satisfaction with the lessons (Q1) and the theme (Q8) and opinion about the difficulty of the theme (Q9) and importance to their future (Q10); as well as the quality of the materials provided (Q11), atmosphere created (Q12), organization (Q13), and support 
provided during the sessions (Q14); four multiple selection questions, asking for students to select among all strategies from the three lessons according to preference (Q4), better comprehension (Q5) and memorization (Q6), and greater difficulty (Q7); two open-ended questions, focused on the advantages of the multisensory instruction (Q3) and improvement proposals or other opinions (Q16); and two yes/no/unsure questions, focused on students' preferences between a more traditional or a multisensory-learning methodology $(\mathrm{Q} 2)$ and their perception of the possible effect of distance education on their learning process $(\mathrm{Q} 15)$ (see the questionnaire in Table 3).

Table 3. Questions composing the final questionnaire and respective answer options.

\begin{tabular}{lc}
\hline \multicolumn{1}{c}{ Question } & Answer \\
\hline Q1: How do you rate your level of satisfaction with the lessons attended? & Likert scale 1-10 \\
\hline $\begin{array}{l}\text { Q2: Do you prefer these lessons over other more common lessons? } \\
\text { (Use exercise resolution lessons as a comparative example) }\end{array}$ & Yes, No, Unsure \\
\hline Q3: What is the main advantage for you of these lessons? & (Open question) \\
\hline Q4: Which of the activities did you enjoy the most? & $\begin{array}{c}\text { Strategies } \\
\text { Activities * }\end{array}$ \\
\hline Q5: Which of the activities helped you understand the subject? & (multiple possible selections) \\
\hline Q6: Which of the activities helped you memorize the subject? & \\
\hline Q7: Which of the activities did you considered the most difficult to perform?
\end{tabular}

Q8: How do you rate your level of satisfaction with the quality of materials and resources used?

Q9: How do you rate your level of satisfaction with this theme?

Q10: How do you rate the level of difficulty associated with this theme?

Q11: How do you rate the level of importance of this theme for your future?

Q12: How do you rate your level of satisfaction with the atmosphere

Likert scale 1-10 created during the lessons?

(Extremely Low-Extremely High)

Q13: How do you rate your level of satisfaction with lesson's organization?

Q14: How to rate your level of satisfaction with the support provided?

Q15: Regarding the last session, do you think that the fact that it occurred by distance education may have negatively affected your learning?

Q16: Do you have any suggestions to improve these lessons, in order to meet your preferences? If so, which one?

Yes, No, Unsure

* Blinded food tasting, disease-related short role-plays, to complete worksheets, dissection of a kidney, assembly and exploring a nephron model, to explore texts and images, to explore rocks and minerals, explanations and conversations, interactive virtual game "the killer element", and none.

\subsection{Validity}

Both tests and the questionnaire were validated after submission to a jury of three supervisors, including two recognized researchers and professors of science education at the Faculty of Sciences at Porto University, and a science teacher who was a supervisor at the school.

\subsection{Reliability}

To ensure reliability of the instruments, both pre- and post-tests were previously applied to a pilot sample of eight external ninth graders from another school. The parallel-forms reliability was analyzed with Spearman's rho correlations coefficient, resulting in a value of 0.75 , which was considered to be acceptable to conduct the study. Regarding the questionnaire, Cronbach's alpha coefficient was applied to determine the internal consistency. A spoken reflection technique was also used to ensure reliability, applied to two ninth-grade external students from a third school. Questions were reformulated in cases where they were unclear or difficult to answer by the students. 


\subsection{Data Analysis}

In order to compare the results obtained for pre- or post-tests for each group, data was first tested to confirm groups, followed a normal sample distribution using the Kolmogorov-Smirnov test, followed by the parametric test two-way analysis of covariance (ANCOVA) on the post-test scores. Levene's test was performed to test for group homogeneity, and homogeneity of the regression slopes was also tested. As for the questionnaire, quantitative data was analyzed by percentage distribution and qualitative data coded and categorized. The anonymous answers to the questionnaire were processed individually through a content analysis of the obtained data, which also consisted of a systematic evaluation of open-ended questions in the questionnaire. All descriptive methods (means and standard deviation) and statistical tests were applied using IBM ${ }^{\circledR}$ SPSS $^{\circledR}$ Statistics 26, Armonk, NY, USA.

\section{Results}

\subsection{Prepost Tests Analyses}

To answer the question proposed, and determine whether there is a significant difference between both groups of students, i.e., between a traditional lesson based on the individual resolution of written exercises and an unconventional lesson built on multisensory strategies, the scores obtained for each of the groups on the pre- and post-tests were analyzed. An independent samples $t$-test analysis showed that there was no statistically significant difference of cognitive performance between the experimental and the control groups for the pretest $(t=0.789$, degrees of freedom $(d f)=78 ; p>0.05)$. Furthermore, paired sample $t$-tests were performed to compare scores obtained in pre- and post-tests for the control group $(t=1.373, d f=37 ; p>0.05)$ and experimental group $(t=-3.302, d f=41 ; p<0.05)$. Means and standard deviations of experimental and control groups in the pre- and post-tests are presented in Table 4 .

Table 4. Means, standard deviations, and standard error mean of the experimental and control groups for the pretest and post-test scores, graded according to a 0-100 scale.

\begin{tabular}{cccccc}
\hline Variable & Group & $\mathbf{n}$ & Mean (\%) & Std. Deviation & Std. Error Mean \\
\hline \multirow{2}{*}{ Pretest } & Control & 38 & 46.51 & 25.51 & 4.14 \\
& Experimental & 42 & 42.32 & 22.01 & 3.40 \\
\multirow{2}{*}{ Post-test } & Control & 38 & 38.87 & 22.14 & 3.59 \\
& Experimental & 42 & 52.66 & 16.86 & 2.60 \\
\hline
\end{tabular}

A two-way ANCOVA was carried out after the reinforcement lesson, with learning methodology and previous retention difference as the independent variables, pretest scores as a covariate, and post-test scores as the dependent variable. The homogeneity of regression slopes and group homogeneity assumptions were met $(p>0.05)$. The statistical analysis indicated that there was a statistically significant difference between the experimental and control groups' mean post-test scores in favor of the experimental group $(\mathrm{F}(1.355)=7.007, p=0.010)$ (Figure 2). Therefore, student's cognitive performances were significantly better for the experimental group engaged in multisensory learning. Regarding the previous retention, the data suggests that there was a significant difference in the favor of students with no previous retention $(\mathrm{F}(1.355)=5.961, p=0.017)$, but there was no significant interaction between treatment and retention differences on cognitive performance $(\mathrm{F}(1.355)=0.038$, $p>0.05)$. The same analysis including gender as an independent variable revealed similar results, with no significant effect of gender on cognitive performance. 


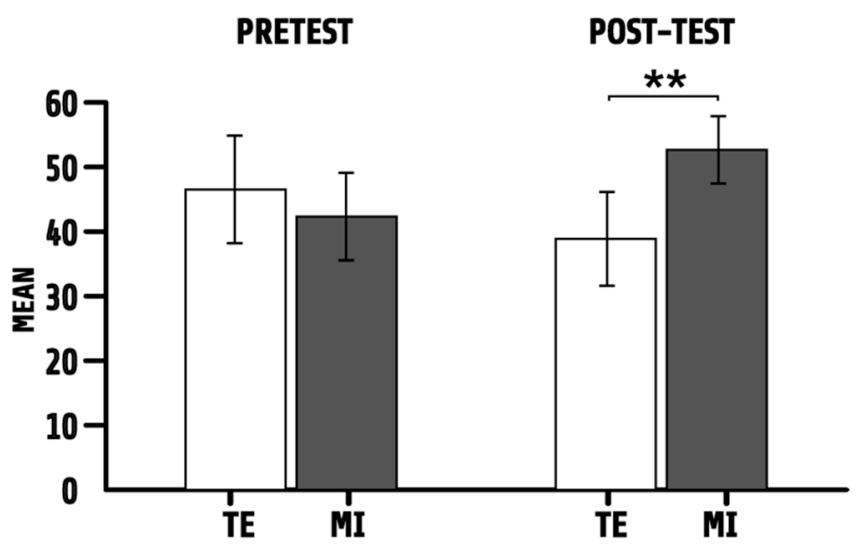

Figure 2. Graphical representation of the mean scores value (error bars: 95\% confidence interval) obtained by the control and experimental groups clustered by pretest and post-test. The students involved in multisensory instruction (MI) during the reinforcement lesson obtained a significantly higher mean value for scores on the post-test compared to students asked to solve textbook exercises as reinforcement lesson $(\mathrm{TE})(* * p$-value $=0.010, \alpha \leq 0.05)$.

\subsection{Questionnaire Analysis}

The questionnaire included eight closed items on a ten-point Likert scale with an internal consistency of 0.85 . According to the 40 questionnaires completed, there was a high satisfaction with the multisensory lessons, with $100 \%$ of responses between 7 to 10 and $87.5 \%$ between 8 to 10 . Multisensory lessons were preferred in $82.5 \%$ of all responses when compared to more traditional lessons, such as solving textbook exercises $(10 \%)$. Nevertheless, $7.5 \%$ of responses indicated "unsure" in the choice between these multisensory lessons and a more traditional one. Regarding the theme "minerals as a link between the Earth and human health", except for one, all responders were very satisfied with the theme selected (7 to 10), with $80 \%$ of all responses considering this theme important for one's future development and $80 \%$ reporting no major difficulties in topic understanding. All the responses reflected satisfaction regarding the quality of the materials and resources provided, general planning and support provided, and the atmosphere created during the three multisensory lessons, with $95 \%$ of responses between 7 to 10 .

Of all the strategies applied in the three multisensory lessons, dissection $(82.5 \%)$, food tasting $(65 \%)$, assembly and exploration of the models (65\%), and breakout virtual games $(52.5 \%)$ were greatly preferred by students. In contrast, discussions (10\%) and worksheets $(7.5 \%)$ were the least selected. Generally, all strategies used were evenly selected for their importance to understanding or remembering the subject, highlighting dissection, followed by models and worksheets, as the most selected, each selected in more than $50 \%$ of all the responses. Additionally, models, worksheets, breakout virtual games, or rock/minerals analysis were selected as the most difficult activities, each selected in $25-30 \%$ of all responses. Moreover, only $35 \%$ of all responses considered that adapting the third lesson to distance learning had no negative effect on the learning process.

The students were also asked to specify the main advantage of the three lessons attended according to their opinion. The advantages of multisensory learning proposed by students were categorized and listed according to the descending frequency of appearance in responses into (1) higher motivation, (2) easy learning, (3) interaction and more practice, (4) better understanding, (5) greater attention or concentration, (6) enhanced memorization, and (7) differentiated learning (Table 5). One student expressed a contrary opinion, claiming there may be no advantages of such lessons. When asked for suggestions to improve classes, in order to meet their learning preferences, almost all students claimed having no other suggestions, and many added their satisfaction. However, one student suggested "more videos" to improve the classes attended. 
Table 5. Categorization of responses to the open-ended item "What is the main advantage of these lessons for you?" and frequency of appearance for each category.

\begin{tabular}{|c|c|c|}
\hline \multicolumn{3}{|c|}{ Advantages of Multisensory Lessons } \\
\hline Advantages & Some Excerpts & $\begin{array}{c}\% \text { in All } \\
\text { Responses }\end{array}$ \\
\hline Higher motivation & $\begin{array}{l}\text { - "I am more attentive because I like the classes better and learn } \\
\text { - } \quad \text { "I a different way." } \\
\text { - "Timore interested in learning." } \\
\text { - " } \quad \text { motivated and willing to work." }\end{array}$ & $35 \%$ \\
\hline Easy learning & $\begin{array}{l}\text { - "Learning in an easier way." } \\
\text { - "We can learn more easily." } \\
\text { - "It is easier to learn and more fun too." }\end{array}$ & $20 \%$ \\
\hline $\begin{array}{l}\text { Interaction and more } \\
\text { practice }\end{array}$ & $\begin{array}{l}\text { - "It is more interactive and better captures students' attention." } \\
\text { - "Learning by practicing." } \\
\text { - "I can better understand the subject, all the schemes and } \\
\text { concepts if I have the possibility to make/move/assemble } \\
\text { structures and observe live than to learn only, for example, } \\
\text { through images." }\end{array}$ & $20 \%$ \\
\hline $\begin{array}{c}\text { Better } \\
\text { Understanding }\end{array}$ & $\begin{array}{l}\text { - "I think we learn faster and these classes make us understand } \\
\text { the subject better." } \\
\text { "The fact that we can see and do, helping us to learn and better } \\
\text { - understand the subject." } \\
\text { "I can understand better." }\end{array}$ & $17.5 \%$ \\
\hline $\begin{array}{l}\text { Greater attention or } \\
\text { concentration }\end{array}$ & $\begin{array}{l}\text { - "I think it draws our attention." } \\
\text { - "It is more interactive and better captures students' attention." } \\
\text { - "I can concentrate better." }\end{array}$ & $10 \%$ \\
\hline $\begin{array}{c}\text { Enhanced } \\
\text { Memorization }\end{array}$ & $\begin{array}{l}\text { - "It is easier to memorize the subjects." } \\
\text { - "Greater ability to retain information." } \\
\text { - "With practical lessons it is easier to memorize knowledge." }\end{array}$ & $10 \%$ \\
\hline Differentiated learning & - "Differentiated learning." & $2.5 \%$ \\
\hline
\end{tabular}

\section{Discussion}

Ours is a multisensory world, where constant sensorial stimuli appeal to us, and objects are analyzed and perceived in a multimodal manner. Furthermore, many of the brain regions previously considered unisensory are de facto multisensory in nature [17]. Therefore, it is reasonable to think that the human brain has developed to operate optimally in a multisensory environment. Multisensory processing and integration are not only highly related to perception and attention [18,19] but, also, to our capability to communicate, write, and read [20,21]. However, still, most schools and teachers choose to follow a predetermined and established "assign and assess" ideology rather than pursuing a more engaging, significant, and long-lasting learning experience. This present work seeks to add to the body of evidence supporting the positive effects of multisensory learning on cognitive and attitudinal parameters (for an overview, see $[2,5,6]$ ).

According to the analysis of classifications obtained on cognitive tests, students attending a multisensory reinforcement lesson had a significantly higher mean value of scores than students taking a conventional lesson guided by textbook exercises, as indicated by the post-test. This was not an aberration, as the answers given by those students in the post-test favored the content learned in the 
multisensory lesson, instead of providing textbook information only. Evidence supports the view that even a single multisensory lesson may play a considerable role in developing the cognitive performance of young students in geoscience classes and appears to be closely related to the process of successful memorization. Positive effects on cognition are partially due to the strategies that promote natural and effortless (episodic) memory development, which, in turn, are closely dependent on meaningful and diversified personal experiences [22]. As suggested before [6,23], the success of multisensory learning may rely on the effectiveness and extent to which such experiences transform into vivid long-lasting memories, requiring creativity and careful preparation and foresight in-line with the topic under study.

In order to further understand the factors behind the improvements of multisensory instruction on cognitive performance, as well as its effect on students' motivation in geosciences classes, an anonymous questionnaire was implemented. The answers revealed a clear preference for multisensory classes among students, and motivation was the most mentioned advantage. Thus, motivation seems to be the most important factor to account for when pursuing better results from students in geosciences classes. Engaging students is and will be one of the biggest challenges for educators. In an era of technological globalization, it is legitimate to consider that new sensory experiences that surprise and captivate youngsters are becoming more difficult to find. Such tasks now require higher creativity levels and walk hand-in-hand with the evolution of our technology [24]. Multisensory approaches are naturally good at providing alternative and diversified learning experiences that appeal to a range of senses, creating different sensations and developing higher levels of motivation, as demonstrated by students' answers to the questionnaire.

Other advantages pointed out by students are, in fact, related to motivation, including greater attention and concentration and ease of learning, which usually arise with good motivation and the effective development of students' understanding and memorization. On the other hand, the interactive character and more practical classes are typical boosters for motivation. However, there may be an effect of novelty associated with multisensory lessons, which are generally less common, which may enhance the student's motivation. However, multisensory approaches, such as those herein presented, are built on multiple strategies, inevitably (and importantly) including more frequently used strategies, such as those associated with auditory and reading/writing perceptual modalities. Moreover, while all students manifested a high level of satisfaction with the lessons, many students preferred previously established strategies, meaning the increase in student's motivation is not solely dependent on new and more interactive activities. One student mentioned differentiated learning as a benefit of multisensory classes, which highlights one of its biggest recognized advantages-to customize instructional strategies to meet a wider range of individual learning preferences or particular intelligence levels [25].

Nonetheless, kinesthetics and movement are essential for early learning, as most young learners are tactile/kinesthetic learners [3,26]. In fact, students preferred more practical and interactive activities, such as dissection, to assemble and explore models and breakout virtual gaming in lieu of fewer interactive activities, such as completing worksheets. Dissection and models were also considered important for understanding and memorization, along with worksheets. Curiously, students attributed a considerable relevance to commonly established tasks such as worksheets due to their importance for understanding and memorization, despite having also shown less motivation and having more difficulty when performing such tasks. This may, in part, reflect an effect of a rooted ideology, cultivated over the years as a habit. Nevertheless, these more traditional strategies are also as important and valid options as any other strategy to be used in multisensory lessons, and were even a preference for some students, so they should not be discarded from multisensory approaches.

The possibilities of multisensory approaches are countless, including a panoply of strategies, but all of them should consistently involve at least two senses in a process of teaching and learning about a specific topic. Unfortunately, vision and hearing are usually the exclusive senses in everyday classes, neglecting the power of touching and manipulating, smelling, and tasting to complement learning experiences. In fact, students clearly preferred activities requiring their taste and smell (food tasting), as well as their manipulation and touch (dissection and models). Understanding our 
multisensory world with all senses should be a golden rule for every educator in teaching. This is particularly relevant in scientific classes, where students learn to understand our human body and surrounding environment.

Interestingly, despite the manifested motivation, many students considered virtual breakout games one of the most difficult activities. These were the main strategy selected for the adaptation of a multisensory class to distance education, imposed by the COVID-19 pandemic, and allowed us to further investigate multisensory learning benefits in this different paradigm. "Nothing replaces the classroom" is a commonly used sentence during this period of transformation. The key message is related to the greater dynamism and flexibility to convey information that face-to-face teaching allows while also easily stimulating new and creative questioning. In addition to being well-established and more intimate, face-to-face teaching is usually more successful, favoring direct relations and synergies between the community, educators, and educational services. Moreover, the traditional classroom instruction eschews dependence on network systems, and the classroom environment itself promotes higher levels of participation, incitement, and direction, unlike face-to-screen teaching, which easily enables students to drop out from online lessons [27]. Therefore, teachers may face new challenges while planning and preparing multisensory approaches in distance education, concerning the struggle to involve senses in a virtual activity and regulate the difficulty, time, and technological issues. For students, lacking the support and attention as given in the classroom may result in disinterest and withdrawal. This study, conducted based on a transition between two opposing paradigms in education, showed that the COVID-19 pandemic had immediate negative effects on the teaching-learning processes from a learner's point of view. According to the questionnaire answers, distance learning was considered by most students an impairment to their learning. Therefore, distance education may be an obstacle to meet multisensory learning benefits, requiring an extra effort on the part of schools, educators, and students to overcome the difficulties.

\section{Limitations and Future Research}

Conducting research within a specific school context frequently poses a threat to purely experimental studies, as random assignment of students to control and experimental groups is usually unattainable, complex, and may raise ethical issues. However, experimental studies are statistically more powerful and allow for generalizations in contrast with quasi-experimental studies such as the present one. Therefore, conducting this research in experimental conditions, when and where this was possible, would add to its value. Future research should explore the potential of multisensory learning further in broader conditions designed to include different schools and/or transcending a variety of school grades, disciplines, and subjects to finally establish and support the widespread inclusion of multisensory approaches in our education systems.

\section{Conclusions}

This study sought to assess the impact of multisensory learning on cognitive performance in geosciences classes and motivation among Portuguese ninth graders when compared to traditional classes, based on textbook written exercises. The multisensory approach selected to teach the importance of minerals in human health in relation to the geosphere and its sustainability led to a significantly higher mean score and promoted the students' motivation. The benefits of a multisensory approach for young students in geosciences education should be recognized, and additional funding, training programs, materials, and resources should be provided for its adequate and optimal utilization by educators and students to avoid sensory-deprived environments.

Author Contributions: Conceptualization, F.M.F.; methodology, F.M.F. and C.V.; validation, C.V.; formal analysis, F.M.F. and C.V.; investigation, F.M.F.; resources, F.M.F.; data curation, F.M.F. and C.V.; writing-original draft preparation, F.M.F.; writing-review and editing, F.M.F. and C.V.; visualization, F.M.F. and C.V.; supervision, C.V.; and project administration, F.M.F. and C.V. All authors have read and agreed to the published version of the manuscript. 
Funding: This research received no external funding.

Acknowledgments: A special thank you to the Rodrigues de Freitas School, both the directors and staff, for making this study possible and providing all the necessary support. The first author would like to express his deep gratitude to Clara Vasconcelos, Alexandra Tabuaço, and his colleague Mariana Melo for their precious help and support.

Conflicts of Interest: The authors declare no conflict of interest.

\section{References}

1. Orton, S.T. Word-blindness in school children. Arch. Neurol. Psychiatry 1925, 14, 581-615. [CrossRef]

2. Gori, M. Multisensory Integration and Calibration in Children and Adults with and without Sensory and Motor Disabilities. Multisens. Res. 2015, 28, 71-99. [CrossRef] [PubMed]

3. Montessori, M. The Montessori Method: Scientific Pedagogy as Applied Child Education in "The Children's Houses", with Additions and Revisions by the Author; George, A.E., Translator; Frederick, A., Ed.; Stokes Company: New York, NY, USA, 1912. [CrossRef]

4. Cardoso, A.; Ribeiro, T.; Vasconcelos, C. What's inside the Earth? Children and seniors' conceptions and the need for a lifelong education. Sci. Educ. 2018, 27, 715-736. [CrossRef]

5. Baines, L. A Teacher's Guide to Multisensory Learning: Improving Literacy by Engaging the Senses; Association for Supervision and Curriculum Development: Alexandria, VA, USA, 2008.

6. Shams, L.; Seitz, A.R. Benefits of multisensory learning. Trends Cogn. Sci. 2008, 12, 411-417. [CrossRef] [PubMed]

7. Brand, S.T.; Dalton, E.M. Universal Design for Learning: Cognitive Theory into Practice for Facilitating Comprehension in Early Literacy. Forum Public Policy 2012, 2012, 1-19.

8. Da Cunha, A.R.F. VARK: Como é que Aprendo Melhor? Uma Mudança no Processo de Ensino-Aprendizagem. Unpublished Master's Thesis, Instituto Politécnico de Viana do Castelo. 2015. Available online: http: //hdl.handle.net/20.500.11960/1582 (accessed on 17 August 2020).

9. Sinclair, S. Creativity, Criticality and Engaging the Senses in Higher Education: Creating Online Opportunities for Multisensory Learning and Assessment. In Creativity \& Critique in Online Learning: Exploring and Examining Innovations in Online Pedagogy; Baxter, J., Callaghan, G., McAvoy, J., Eds.; Palgrave Macmillan: London, UK, 2018; pp. 103-122. [CrossRef]

10. Orion, N.; Libarkin, J. Earth systems education. In Handbook of Research on Science Teaching and Learning; Abell, S., Lederman, N., Eds.; Lawrence Erlbaum Associates: Mahwah, NJ, USA, 2014. [CrossRef]

11. Vasconcelos, C.; Ferreira, F.; Rolo, A.; Moreira, B.; Melo, M. Improved concept map-based teaching for an Earth system approach. Geosciences 2020, 10, 8. [CrossRef]

12. Rodrigues, I.; Torres, J.; Favas, P. Geomedicine and History of Science: A Contribution to Scientific Culture. In Geoscience Education: Indoor and Outdoor; Vasconcelos, C., Ed.; Springer: Berlin/Heidelberg, Germany, 2016; pp. 207-224. [CrossRef]

13. Skinner, H.C.W. The Earth, Source of Health and Hazards: An Introduction to Medical Geology. Annu. Rev. Earth Planet. Sci. 2007, 35, 177-213. [CrossRef]

14. National Research Council. Aging and the Geochemical Environment; The National Academies Press: Washington, DC, USA, 1981. [CrossRef]

15. United Nations General Assembly. Transforming Our World: The 2030 Agenda for Sustainable Development (Resolution Adopted by the General Assembly on 25 September 2015: 70/1). 2015. Available online: https://www.un.org/ga/search/view_doc.asp?symbol=A/RES/70/1\&Lang=E (accessed on 1 September 2020).

16. Airasian, P.W.; Cruikshank, K.A.; Mayer, R.E.; Pintrich, P.R.; Raths, J.; Wittrock, M.C. A Taxonomy for Learning, Teaching, and Assessing: A Revision of Bloom's Taxonomy of Educational Objectives (Complete Edition); Anderson, L.W., Krathwohl, D.R., Eds.; Longman: London, UK, 2001.

17. Ghazanfar, A.A.; Schroeder, C.E. Is neocortex essentially multisensory? Trends Cogn. Sci. (Regul. Ed.) 2006, 10, 278-285. [CrossRef] [PubMed]

18. Matusz, P.J.; Broadbent, H.; Ferrari, J.; Forrest, B.; Merkley, R.; Scerif, G. Multi-modal distraction: Insights from children's limited attention. Cognition 2015, 136, 156-165. [CrossRef] [PubMed]

19. Shimojo, S.; Shams, L. Sensory modalities are not separate modalities: Plasticity and interactions. Curr. Opin. Neurobiol. 2001, 11, 505-509. [CrossRef] 
20. Bishop, C.W.; Miller, L.M. A multisensory cortical network for understanding speech in noise. J. Cogn. Neurosci. 2009, 21, 1790-1804. [CrossRef] [PubMed]

21. Vickery, K.S.; Reynolds, V.A.; Cochran, S.W. Multisensory teaching approach for reading, spelling, and handwriting, Orton-Gillingham based curriculum, in a public school setting. Ann. Dyslexia 1987, 37, 189-200. [CrossRef] [PubMed]

22. Banikowski, A.; Mehring, T. Strategies to Enhance Memory Based on Brain Research. Focus Except. Child. 1999, 32, 1-16. [CrossRef]

23. Bagui, S. Reasons for increased learning using multimedia. J. Educ. Multimed. Hypermedia 1998, 7, 3-18. [CrossRef]

24. Henriksen, D.; Henderson, M.; Creely, E.; Ceretkova, S.; Černochová, M.; Sendova, E.; Sointu, E.T.; Tienken, C.H. Creativity and Technology in Education: An International Perspective. Technol. Knowl. Learn. 2018, 23, 409-424. [CrossRef]

25. Stone, P. How we turned around a problem school. The problem wasn't our students couldn't learn; it was that we didn't know how to teach them. Principal 1992, 72, 34-36.

26. Price, G.E.; Dunn, R.; Sanders, W. Reading achievement and learning style characteristics. Clear. House 1980, 54, 223-226. [CrossRef]

27. Kemp, N.; Grieve, R. Face-to-Face or face-to-screen? Undergraduates' opinions and test performance in classroom vs. online learning. Front. Psychol. 2014, 5, 1278. [CrossRef] [PubMed]

Publisher's Note: MDPI stays neutral with regard to jurisdictional claims in published maps and institutional affiliations.

(C) 2020 by the authors. Licensee MDPI, Basel, Switzerland. This article is an open access article distributed under the terms and conditions of the Creative Commons Attribution (CC BY) license (http://creativecommons.org/licenses/by/4.0/). 